\title{
Research of Cu-Doped Hydroxyapatite Microbeads Fabricated by Pneumatic Extrusion Printing
}

\author{
Wenchao Chi ${ }^{1,+}$, Jiawei Zou ${ }^{1, \dagger}$, Fanrong Ai ${ }^{1,2}$, Yanjun Lin ${ }^{1}$, Wenchao Li ${ }^{1}$, Chuanliang Cao ${ }^{1}$, \\ Kang Yang ${ }^{3}$ and Kui Zhou 1,2,4,* \\ 1 School of Mechatronics Engineering, Nanchang University, Nanchang 330031, China; \\ wcchi@email.ncu.edu.cn (W.C.); JiaweiZOU@email.ncu.edu.cn (J.Z.); aifanrong@ncu.edu.cn (F.A.); \\ yjlin@email.ncu.edu.cn (Y.L.); Chadli@ncu.edu.cn (W.L.); cl_cao@ncu.edu.cn (C.C.) \\ 2 Key Laboratory of Lightweight and high strength structural materials of Jiangxi Province, \\ Nanchang University, Nanchang 330031, China \\ 3 College of Pharmacy, Nanchang University, Nanchang 330031, China; yangkang@email.ncu.edu.cn \\ 4 Engineering Science and Mechanics Department, Penn State University, University Park, PA 16802, USA \\ * Correspondence: zhoukui@ncu.edu.cn \\ + Wenchao Chi and Jiawei Zou contributed equally to this article.
}

Received: 23 April 2019; Accepted: 28 May 2019; Published: 31 May 2019

\begin{abstract}
Copper is an indispensable micronutrient in human health, which has important effects on the promotion of angiogenesis and thus contributes to bone formation and antimicrobial activity. We used ion exchange and pneumatic printing methods to prepare hydroxyapatite (HA) microspheres with different copper content. The microspheres were characterized by scanning electron microscope (SEM), X-ray diffractometry (XRD) and X-Ray photoelectron spectroscopy (XPS). Considering the resistance of hydroxyapatite to biodegradation in vivo, the degradation rate of microspheres in modified simulated body fluids was studied. In addition, cell proliferation and antibacterial experiments were carried out to study the biological properties of microspheres. HA-1.5MCu microbeads treated by $1.5 \mathrm{~mol} / \mathrm{L} \mathrm{CuSO}_{4}$ curing solution have good performance on degradation, antibacterial properties and cell survival rate on day 7 . The results showed that HA-1.5MCu microbeads may be used as a good repair material for bone defects.
\end{abstract}

Keywords: hydroxyapatite; microbeads; copper; biological performance

\section{Introduction}

Hydroxyapatite $\left(\mathrm{Ca}_{10}\left(\mathrm{PO}_{4}\right)_{6}(\mathrm{OH})_{2}, \mathrm{HA}\right)$ is the main inorganic component of the human skeleton. HA is widely used in hard tissue repair and replacement due to its good biocompatibility and bioactivity. However, the main component of human bone mineral is not pure HA, but the typical calcium-deficient $\mathrm{HA}$, whose expression is $\mathrm{M}_{10}\left(\mathrm{ZO}_{4}\right)_{6} \mathrm{X}_{2}$. $\mathrm{M}$ is an alternative position that can be replaced by cations (such as $\mathrm{Mg}^{2+}, \mathrm{Zn}^{2+}, \mathrm{Sr}^{2+}, \mathrm{Cu}^{2+}$ ) [1]. Hydroxyapatite ceramic microspheres play an important role in cancer therapy, antibacterial therapy, and other biomedical applications [2,3]. In addition, ceramic microspheres can be widely used in stomatology and bone defect filling in other parts of human bones [4].

Moreover, copper-doped microspheres have their own unique functions. Copper, as the second essential trace element in human body, plays an important role in the human metabolism [5]. Copper can promote the growth of vascular endothelial cells and facilitate angiogenesis [6]. At the same time, copper can promote the formation of collagen, thereby maintaining the normal composition and structure of bones and inhibiting osteoporosis [7]. In addition, copper has good antibacterial activity against both gram-positive and negative bacteria [8]. Therefore, the addition of copper to the synthetic 
HA microsphere is expected to improve its biological properties and give it an antibacterial function. Currently, copper-doped HA is the main preparation method for copper-doped microspheres, while the main synthesis methods for copper-doped HA include chemical coprecipitation [9], high-temperature solid-phase synthesis [10], and ion exchange [11]. The process of chemical coprecipitation is simple, but the product has poor crystallinity and low purity [9]. High temperature solid phase synthesis requires high reaction temperature, and the product is easy to agglomerate. However, the above methods have the disadvantages of complex and unstable processes, and no one has studied how to turn doping copper into commercial HA powders. Copper alginate colloidal spheres can be produced by dropping alginate solution into aqueous solution containing copper ions, and then the copper-doped microspheres can be produced by sintering.

The copper-doped hydroxyapatite ceramic microspheres were obtained by the pneumatic printing method. The sintering process was determined by thermogravimetric analysis (TGA). The effects of different doping amounts on the physicochemical and biological properties of hydroxyapatite ceramic microspheres were investigated. The physical properties of hydroxyapatite ceramic microspheres were characterized by X-ray diffractometry (XRD), X-Ray photoelectron spectroscopy (XPS), and scanning electron microscope (SEM). The effects of different doping amounts on the water absorption and degradation rate were also studied. The biological properties of $\mathrm{Cu}$-doped microspheres were characterized by antibacterial and cell experiments.

\section{Materials and Methods}

\subsection{Materials}

Nano HA powder (needle like particle, $60 \mathrm{~nm}$ width and $150 \mathrm{~nm}$ length) was supplied by Emperor Nano Material, China. Sodium alginate (SA) used in the experiment was purchased from Aladdin Industrial Inc. $\mathrm{CuSO}_{4} \cdot 5 \mathrm{H}_{2} \mathrm{O}$ (analytical grade) were obtained from Sinopharm Chemical Reagent Co. Ltd.

\subsection{Preparation of $\mathrm{Cu}$-doped HA Microbeads via Pneumatic Extrusion Printing}

$\mathrm{Cu}$-doped HA microbeads were fabricated through the preparation protocols illustrated in Figure 1. First, the HA suspension was prepared. In a typical experiment, $1 \mathrm{~g}$ of sodium alginate and $10 \mathrm{~g}$ HA powder were added to $100 \mathrm{~g}$ distilled water with continuous stirring by juice extractor to obtain homogeneous HA suspension. After the suspension was prepared, it was printed into $\mathrm{CuSO}_{4}$ solutions by a homemade pneumatic extrusion printing to obtain microbeads. A cone angle needle with an inner diameter of $0.6 \mathrm{~mm}$ was used. The printing parameters for positive pressure, negative pressure, dwell time and collecting distance were $30 \mathrm{kPa}, 7 \mathrm{kPa}, 10 \mathrm{~ms}, 60 \mathrm{~mm}$, respectively. The obtained HA microbeads were crosslinked in $\mathrm{CuSO}_{4}$ solutions $(0.1 \mathrm{~mol} / \mathrm{L}, 0.5 \mathrm{~mol} / \mathrm{L}, 1.0 \mathrm{~mol} / \mathrm{L}$ and $1.5 \mathrm{~mol} / \mathrm{L}$ ) for $24 \mathrm{~h}$ and dried at room temperature, named as HA-0.1MCu, HA- $0.5 \mathrm{MCu}, \mathrm{HA}-1 \mathrm{MCu}$ and HA-1.5MCu microbeads respectively. Prior to the sintering step, the TGA of HA-0.5MCu microbeads was conducted from $30^{\circ} \mathrm{C}$ to $900{ }^{\circ} \mathrm{C}$ at a heating rate of $10^{\circ} \mathrm{C} / \mathrm{min}$, using a PerkinElmer TGA-4000 apparatus (Perkin-Elmer, Wellesley, USA). The optimal sintering parameters of the dried microbeads were defined as: (1) pre-sintered at $400{ }^{\circ} \mathrm{C}$ for $1 \mathrm{~h}$; and (2) Sintered at $1200^{\circ} \mathrm{C}$ for $2 \mathrm{~h}$ using a commercial oven (SX2-10-13, Jiangsu qianjin furnace industry, China). 


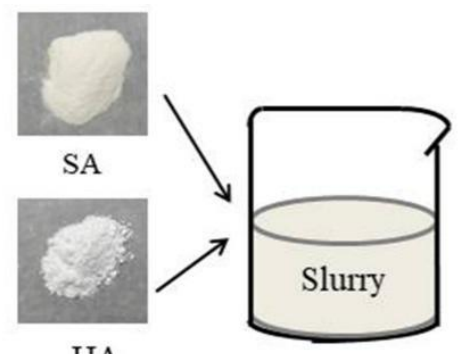

HA

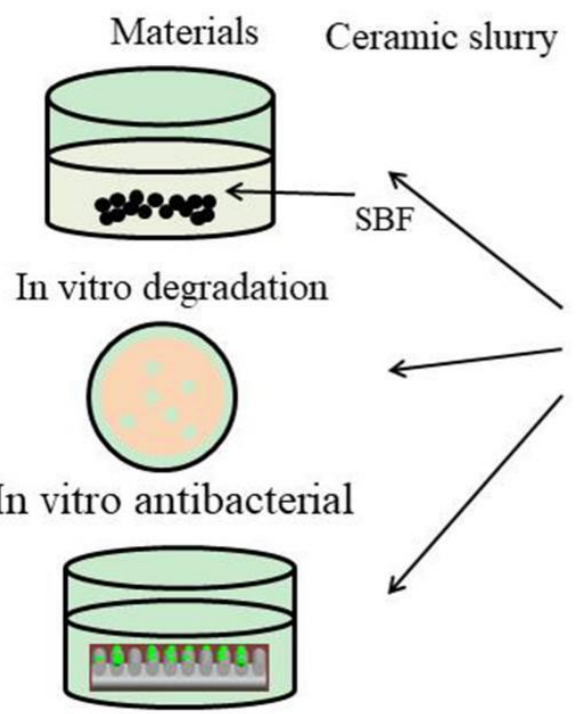

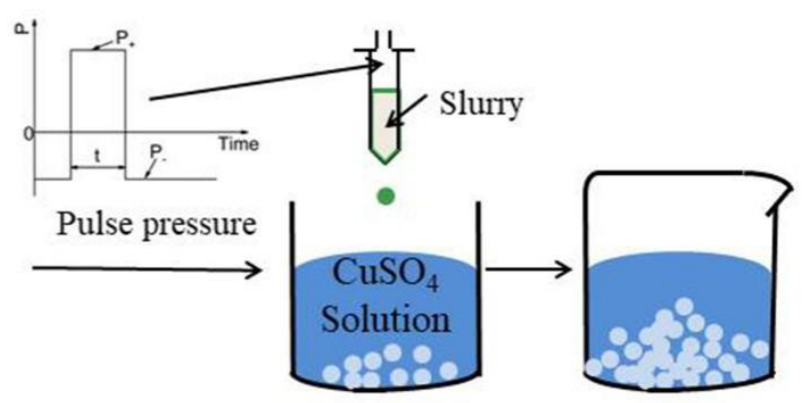

3D Pneumatic printing Crosslinking

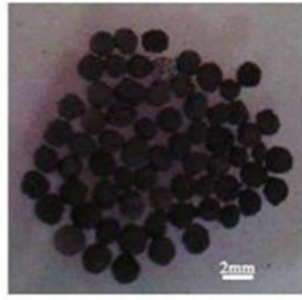

Sintering sample

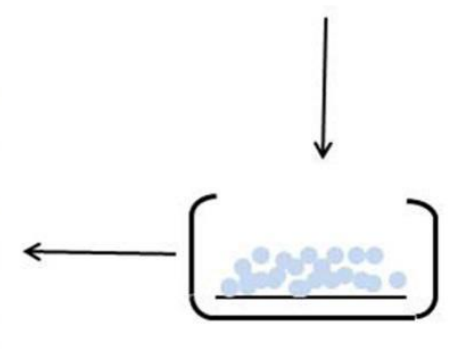

Drying and sintering

In vitro cell culture

Figure 1. Schematic representation of the preparation protocol for the $\mathrm{Cu}$-doped hydroxyapatite (HA) macrobeads.

\subsection{Characterization of $\mathrm{Cu}$-Doped HA Microbeads}

\subsubsection{Physico-Chemical Characterization}

The morphologies of the sintered $\mathrm{Cu}$-doped HA microbeads were characterized by SEM (SIGMA300, Zeiss, Jena, Germany) at an operating voltage of $3 \mathrm{kV}$ after sputtered-coated with gold. The phases of microbeads were characterized by X-ray diffractometry (D8 ADVANCE, BRUKER, Karlsruhe, Germany), using $40 \mathrm{kV}, 40 \mathrm{~mA}, \mathrm{Cu} \mathrm{K} \alpha$ X-rays. The XRD test conditions were as follows: scan rate $4 \%$ min, step $0.02^{\circ}$, scan range $20^{\circ}-60^{\circ}$ and X-ray wavelength $\lambda=0.1542 \mathrm{~nm}$. X-Ray photoelectron spectroscopy (XPS ESCALAB250Xi, ThermoFisher Scientific, Waltham, USA) of the samples was undertaken out using a ThermoFisher Scientific ESCALAB250XiX spectrometer to investigate the successful doping of HA with $\mathrm{Cu}$. Al-K $\alpha$ irradiation was used for the target (1486.6 eV). The beam spot size was $650 \mu \mathrm{m}$. Survey scans were recorded with a $0.1 \mathrm{eV}$ step and $30 \mathrm{eV}$ pass energy. The water absorption tests were carried out by soaking samples in distilled water for $24 \mathrm{~h}$ and then tapered with a soft paper towel to remove excess water from the specimen surface [12]. The water absorption (WA \%) was calculated according to the following equation:

$$
\mathrm{WA}(\%)=\frac{W_{1}-W_{2}}{W_{1}} \times 100
$$

where $\mathrm{W}_{1}$ and $\mathrm{W}_{2}$ are weights of the sintered Cu-doped HA microbeads before and after immersing in distilled water of $24 \mathrm{~h}$, respectively. The weight of $\mathrm{Cu}$-doped HA microbeads were characterized by an electronic analytical balance (JJ224BF Changshu Shuangjie test instrument factory China). The accuracy of the analytical balance was $0.0001 \mathrm{~g}$. Four parallel samples ( $\sim .9 \mathrm{~g}$ microbeads for each sample) were 
used for the water absorption test. Since HA degrades very slowly in a neutral environment [13], the acidic simulated body fluid $(\mathrm{SBF}, \mathrm{pH}=3)$ was used in this study to accelerate the degradation process [14]. Cu-doped HA microbeads were immersed into SBF solution with solid/liquid ratio of $0.1 \mathrm{~g} / \mathrm{mL}$. The SBF solution was changed every day. The microbeads were removed from the SBF at day $0,1,3,5,7,10,14$ and 17, dried in a drying oven. The percentage of weight loss was calculated as follows:

$$
\text { Weight } \operatorname{Loss}(\%)=\frac{M_{0}-M}{M_{0}} \times 100
$$

where $M_{0}$ is the starting dry weight and $M$ is the dry weight at day $t$. Weight loss experiments were performed in three trials. Electronic analytical balance (JJ224BF Changshu Shuangjie test instrument factory China, accuracy is $0.0001 \mathrm{~g}$ ) was used to measure the weight of $\mathrm{Cu}$-doped HA microbeads.

\subsubsection{Antimicrobial Analysis}

S. aureus and E. coli are clinically common pathogenic bacteria. The antibacterial activity of the Cu-doped HA microbeads against S. aureus (ATCC 25923) and E. coli (ATCC 25922) [15] was studied using the mean colony-forming units method. $0.025 \mathrm{~g}$ Cu-doped HA microbeads were put into a flask containing $2 \mathrm{~mL}$ bacterial suspension and incubated at $37^{\circ} \mathrm{C}$ for $24 \mathrm{~h}$. The samples were taken out and $100 \mu \mathrm{L}$ of $10^{-6}$ dilutions were plated out on TSA plates and incubated overnight at $37^{\circ} \mathrm{C}$. The colonies were counted on the following day. The number of viable microorganism colonies was determined using the method of plate counting and the antibacterial ratio was calculated as follows:

$$
\text { Antibacterial ratio }(\%)=\frac{N_{1}-N_{2}}{N_{1}}
$$

where $N_{1}$ is the average value of survived bacteria incubated with control groups, and $N_{2}$ is the number of survived bacteria incubated with $\mathrm{Cu}$-doped HA microbeads. The experiments were carried out in triplicate to confirm reproducibility.

\subsubsection{In Vitro Cell Culture Evaluation}

To prepare $\mathrm{Cu}$-doped HA microbeads extracts, $0.05 \mathrm{~g}$ of microbeads were placed into $2.5 \mathrm{~mL}$ of complete culture medium. The medium was then incubated at $37^{\circ} \mathrm{C}$ (in a humidified atmosphere of $5 \% \mathrm{CO}_{2}$ ) for $24 \mathrm{~h}$. Then, the extract was collected from the medium. Such obtained extracts were subjected to evaluation of cell proliferation. Bone marrow mesenchymal stem cells (BMMSCs) [16], harvested from one month old male SD rats, were used to assess the cytocompatibility of the microbeads. BMMSCs were co-cultured with $10 \mu \mathrm{L} \mathrm{Cu}$-doped HA microbeads extracts at a density of $2 \times 10^{3}$ cells/well in 96-well plate. The Cell Counting Kit-8 assay (CCK8; Dojindo Molecular Technologies Inc., Japan) were tested after day 1, day 3 and day 7 . The relative increase in the rate of cells in each experimental group was calculated by the mean value of the absorbance of the blank control group being $100 \%$ cell proliferation rate. Three parallel samples were used for the cell culture experiment.

\subsubsection{Statistical Analyses}

The data was expressed as mean \pm standard deviation (SD). Statistical analysis was performed on Statistical Product and Service Solutions software (SPSS 17.0, IBM, USA) using one-way ANOVA, followed by the Tukey post hoc test for multiple groups comparison. A p value $<0.05$ was considered to be statistically significant.

\section{Results and Discussion}

TGA experiments were used to validate the loss of mass during the sintering. The TGA curves shown in Figure 2 exhibit three stages of weight loss up to $900{ }^{\circ} \mathrm{C}$. The first drop in the weight loss around $100^{\circ} \mathrm{C}$ is due to the loss of water in the scaffold. Then the second weight loss that occurs between $200{ }^{\circ} \mathrm{C}$ and $400{ }^{\circ} \mathrm{C}$ can be associated with the pyrolysis of salt alginate. The last weight loss above 
$850{ }^{\circ} \mathrm{C}$ is due to the decomposition of the pyrolysis product of salt alginate and the dehydroxylation behavior of HA. Thus, a staged sintering process was used in this research.

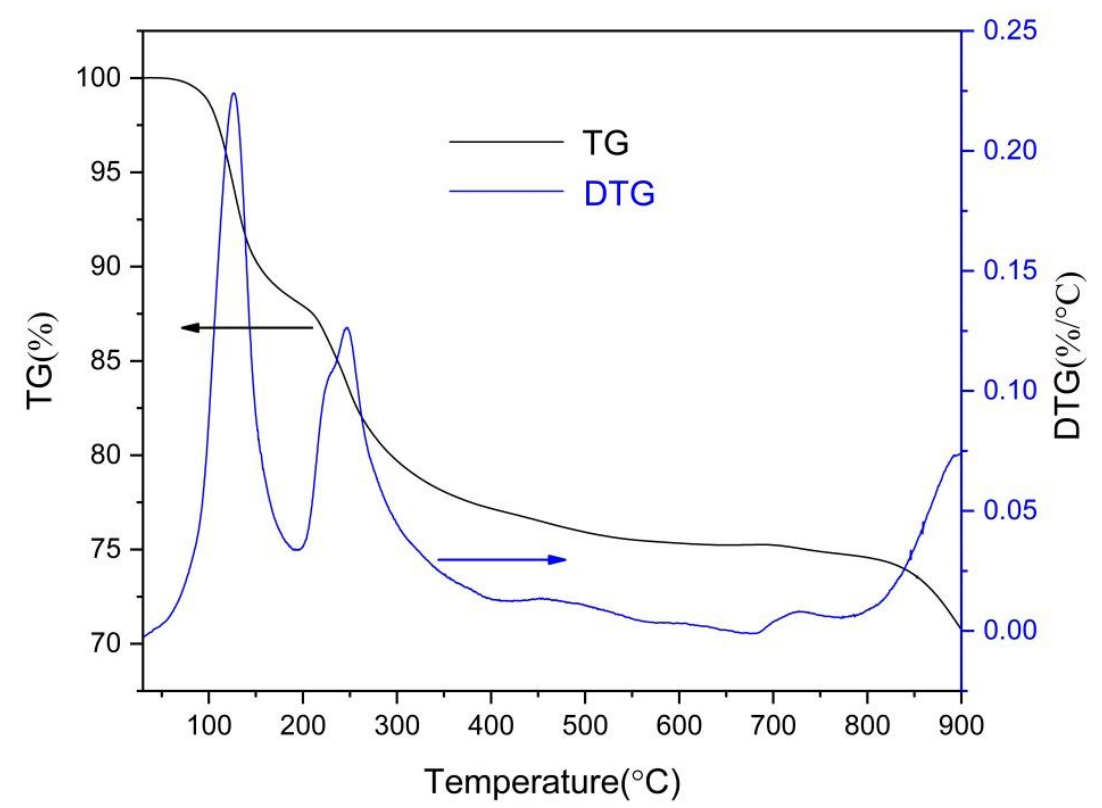

Figure 2. Thermogravimetric analysis (TGA) curves of HA-0.5MCu macrobeads.

The SEM images of the surface cross-section of the sintered microbeads are shown in Figure 3. The Cu-doped microspheres with HA-0.1MCu have good microbeads shape on a macroscopic and compact surface structure on microscopic. With the increase of curing solution concentration, the surface of the copper-doped microbeads becomes rougher at the macro level. In particular, HA-1.0MCu and HA-1.5MCu microbeads show obvious uneven structure at the micro level, but maintain a good microbeads shape on the whole.

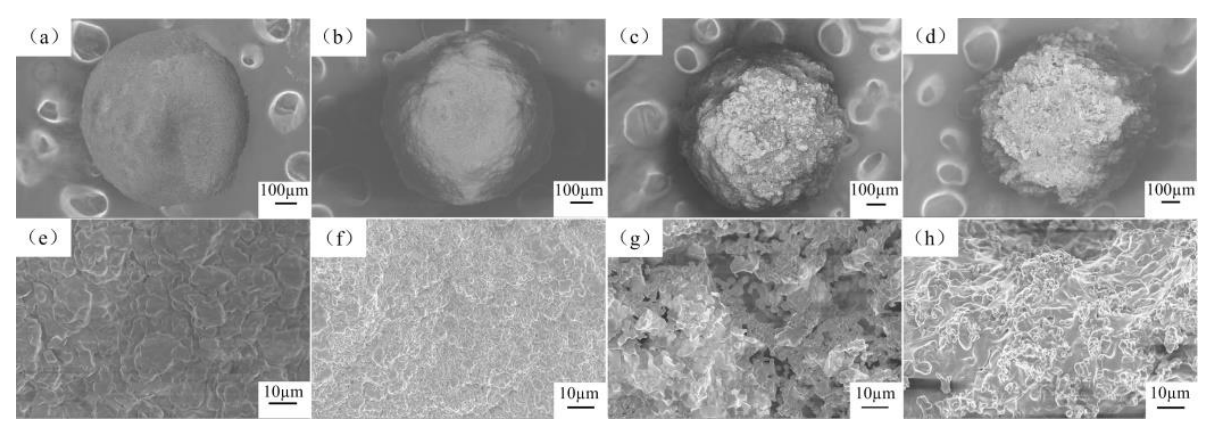

Figure 3. Scanning electron micrograph of $\mathrm{Cu}$-doped HA macrobeads: (a,e) HA-0.1MCu, (b,f) HA-0.5MCu, (c,g) HA-1.0MCu, (d,h) HA-1.5MCu.

In order to further explore the microstructure of $\mathrm{Cu}$ doped microbeads, the water absorption rate of $\mathrm{Cu}$ doped microbeads was studied by liquid replacement method [17] at room temperature. The water absorption rate images are shown in Figure 4. The results showed that the water absorption rate of HA-1.0MCu and HA-1.5MCu microspheres was significantly higher than that of HA-0.1MCu microspheres. Combining with SEM results, it may be due to the HA-1.0MCu and HA-1.5MCu microbeads having a rougher surface structure. 


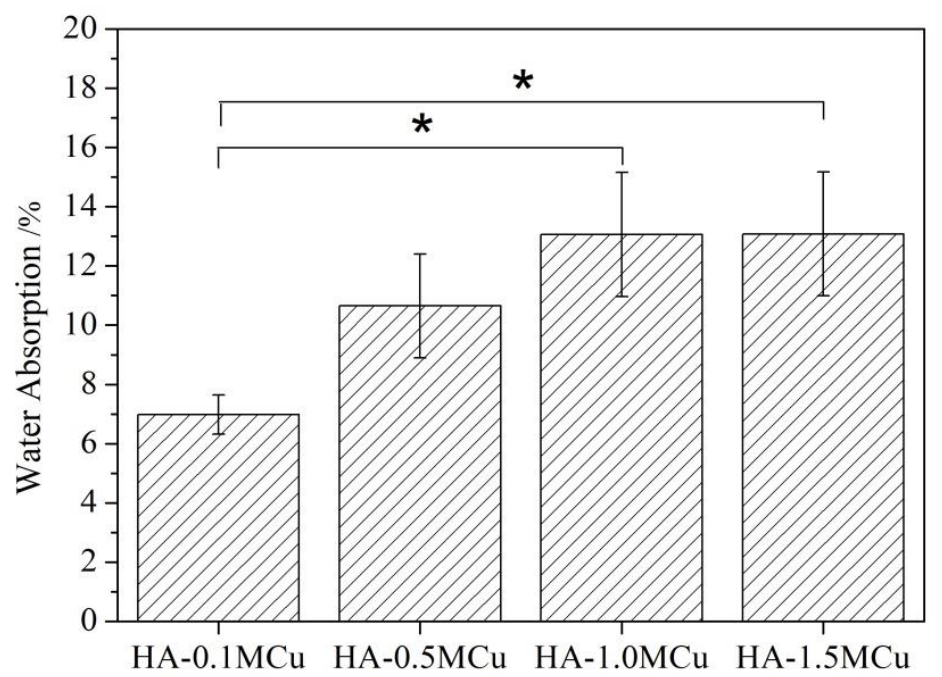

Figure 4. Water absorption of Cu-doped HA macrobeads after sintering. Asterisks $\left({ }^{*}\right)$ denote. significant differences $(* p<0.05)$.

The XRD patterns of the Cu-doped microbeads after sintered at $1200^{\circ} \mathrm{C}$ are shown in Figure 5 . Similar to the XRD lines of $\mathrm{Cu}$ doped microbeads, all of the $\mathrm{Cu}$-doped microbeads are composed of hydroxyapatite (JCPDS-PDF: 09-0432) [12], tricalcium phosphate [18] (JCPDS-PDF: 70-2065), copper oxide (JCPDS-PDF: 80-0076) and cuprous oxide [19] (JCPDS-PDF: 78-2076). Hydroxyapatite will convert into tricalcium phosphate when the temperature is above $130{ }^{\circ} \mathrm{C}$ [20]. But in this experiment, tricalcium phosphate was produced in $1200^{\circ} \mathrm{C}$. The reason may be that the incorporation of copper leads to lower temperature of hydroxyapatite converted into tricalcium phosphate [21]. A similar phenomenon can be seen in Silva's study [22]. Zn-alginate-hydroxyapatite composite spheres were produced in a solution rich in zinc ions. During sintering, zinc ions entered the hydroxyapatite structure and induced its decomposition to $\beta$-TCP. The pyrolysis of copper alginate produces copper oxide and cuprous oxide.

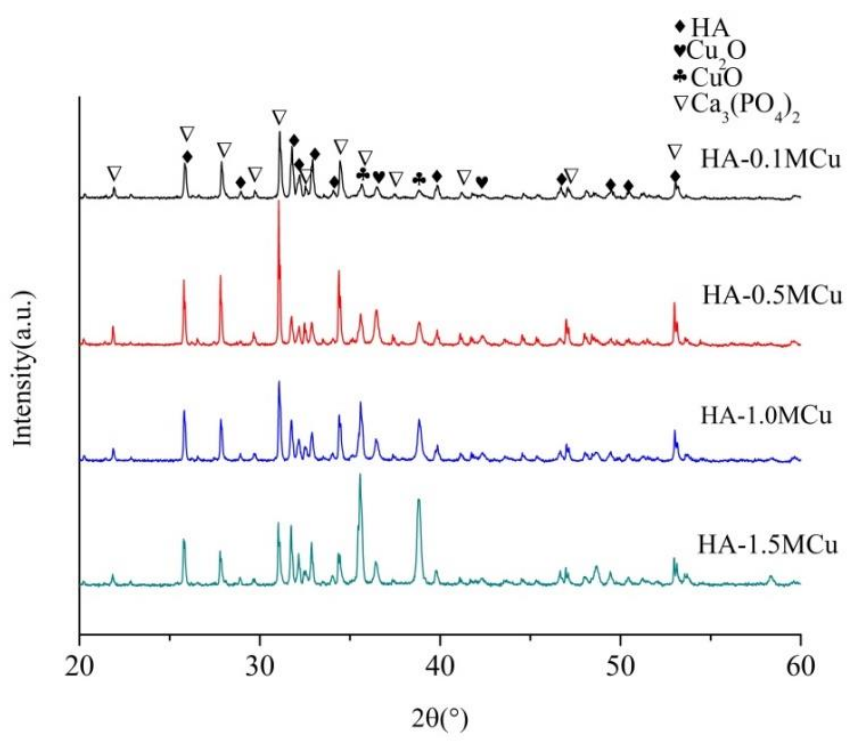

Figure 5. XRD patterns of Cu-doped HA macrobeads after sintering.

The XPS patterns of $\mathrm{Cu}$-doped HA microbeads after sintering at $1200{ }^{\circ} \mathrm{C}$ are shown in Figure 6 . The sintered microspheres mainly contained $\mathrm{Ca}, \mathrm{P}, \mathrm{O}$ and $\mathrm{Cu}$ elements. The atomic ratios of $\mathrm{Ca}, \mathrm{P}$, $\mathrm{O}$ and $\mathrm{Cu}$ are shown in the Figure. With the increase of the concentration of curing solution, the 
amount of copper in the microspheres increased. When the concentration was low $(0.1 \mathrm{~mol} / \mathrm{L}, 0.5 \mathrm{~mol} / \mathrm{L}$, $1.0 \mathrm{~mol} / \mathrm{L})$, the content of copper in the microspheres increased rapidly, while when the concentration reached $1.0 \mathrm{~mol} / \mathrm{L}$, the increase of copper content slowed down. Therefore, the doping amount of copper can be adjusted by adjusting the concentration of the curing solution.

(a)

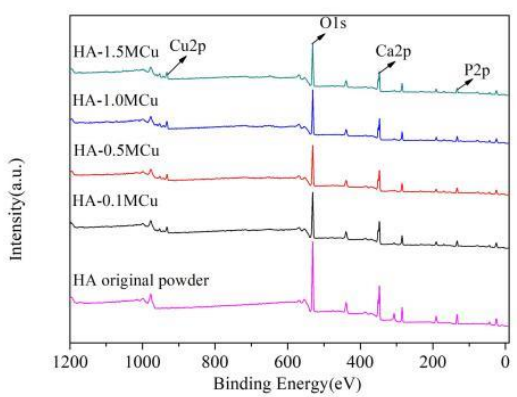

(b)

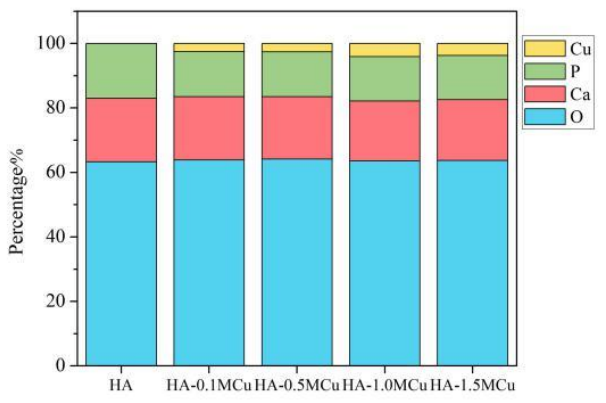

Figure 6. XPS patterns of $\mathrm{Cu}$-doped HA macrobeads after sintering (a) and atomic ratio of $\mathrm{Ca}, \mathrm{P}, \mathrm{O}$ and $\mathrm{Cu}(\mathbf{b})$.

The degradation properties of $\mathrm{Cu}$-doped beads were determined. According to the Figure 7, the degradation rate of $\mathrm{HA}-1.0 \mathrm{MCu}$ and $\mathrm{HA}-1.5 \mathrm{MCu}$ copper-doped microspheres was significantly faster than that of $\mathrm{HA}-0.1 \mathrm{MCu}$ and $\mathrm{HA}-0.5 \mathrm{MCu}$ copper-doped microspheres. The reason is that HA-1.0MCu and HA-1.5MCu copper-doped microspheres have a relatively rougher surface structure. As a result, the contact area between the microspheres and $\mathrm{SBF}(\mathrm{pH}=3)$ during the degradation process is larger, so the degradation rate of $\mathrm{HA}-1.0 \mathrm{MCu}$ and $\mathrm{HA}-1.5 \mathrm{MCu}$ copper-doped microspheres is faster. Nevertheless, the degradation process of all microspheres showed a similar trend, that is, the degradation degree increased with the increase of degradation time.

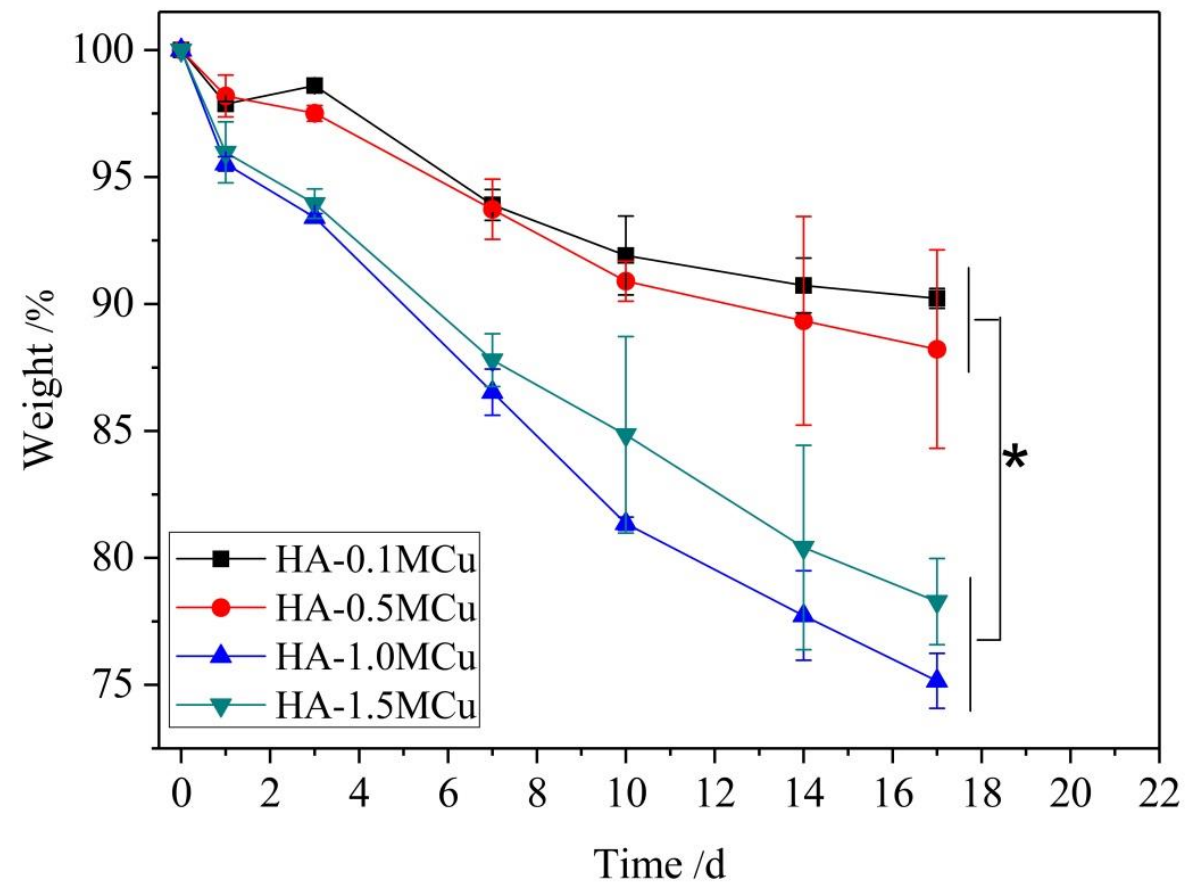

Figure 7. Weight loss rate of sintered $\mathrm{Cu}$-doped HA macrobeads in acidic $\mathrm{SBF}(\mathrm{pH}=3) .\left({ }^{*} p<0.05\right)$.

The effect of copper ions in copper-doped microspheres on the antimicrobial activity was determined by plate method using E. coli and S. aureus strains. The possible mechanism of action of copper as an antibacterial agent in microspheres could be due to the interaction of copper ions with 
the outer membrane of the bacteria and thereby causing structural damage and finally bacteria death. According to the Figure 8, we can see that the antibacterial activity of $\mathrm{Cu}$-doped microspheres against gram-negative bacteria was higher than that of gram-positive bacteria [23]. However, the antimicrobial activity of HA-1.0MCu and HA-1.5MCu copper-doped microspheres was significantly higher than that of HA-0.1MCu copper-doped microspheres. The reason is that copper has good antibacterial performance [24], and compared with HA-0.1MCu copper doped microspheres, HA-1.0MCu and HA-1.5MCu copper doped microspheres have higher $\mathrm{Cu}$ content and rougher surface structure. As a result, the copper-doped microspheres of $\mathrm{HA}-1.0 \mathrm{MCu}$ and $\mathrm{HA}-1.5 \mathrm{MCu}$ lead to more $\mathrm{Cu}$ elements diffusing into the leaching solution, which improves the antimicrobial performance of the microspheres. Thus, the antimicrobial effect can be improved by tailoring the parameters of the concentration of the curing solution.
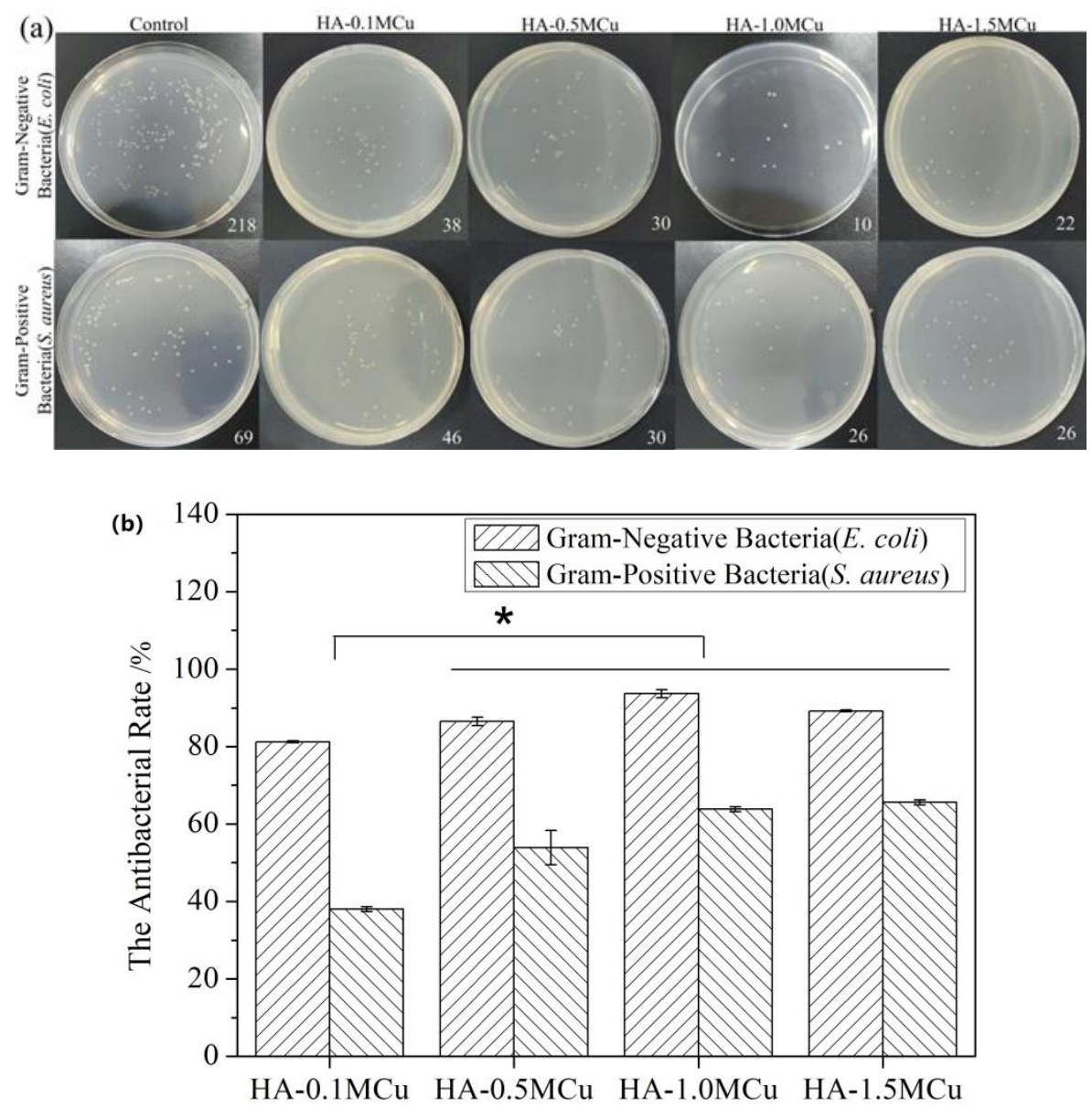

Figure 8. Antibacterial rate against E. coli and S. aureus. $\left({ }^{*} p<0.05\right)$. (a) Plate counting photographs; (b) quantitative antibacterial results.

The cell survival rates are shown in Figure 9. It can be seen that the cell survival rate of the HA-1.0MCu and HA-1.5MCu microspheres on day 1 was significantly lower than that of the control group on day 1 . The cell survival rate of the HA-0.1MCu, HA-0.5MCu, HA-1.0MCu and HA-1.5MCu microspheres on day 3 was significantly lower than that of the control group on day 3 . There was no significant difference between the cell survival rate on day 7 and that of the control group on day 7 . This indicates that the presence of $\mathrm{Cu}$ ion has obvious cytotoxicity at the early stage of the experiment. The higher the concentration of copper ions, the greater the cytotoxicity. However, the cell survival rate of $\mathrm{HA}-0.5 \mathrm{MCu}$ on day 7 was significantly higher than that of $\mathrm{HA}-0.5 \mathrm{MCu}$ on day 1 , and that of HA-1.5MCu on day 7 was significantly higher than that of HA-1.5MCu on day 1, indicating that the microspheres of HA-0.5MCu and HA-1.5MCu promoted the cell survival in the later stage of the 
experiment. The reason may be that copper ions have two effects on cell proliferation activity. On the one hand, copper ion incorporation positively promoted the expression of hypoxia-inducible factor 1-alpha in BMMSCs and promoted the proliferation activity of cells [25]. On the other hand, when the concentration of copper ions is high, it has an inhibitory effect on cell proliferation activity [26]. On the first and third days, the cell survival rate decreased with an increase in the concentration of copper ions, which may be due to the toxicity of copper ion. By day 7, the burst release period of copper ions had passed and the cells had adapted to the environment. Thus the positive effect of copper ions on cell proliferation activity began to emerge, which directly resulted in the cell survival rate of the experimental group began to increase, and with the increase of copper content in the microspheres, the cell survival rate also increased. The promoting effect of HA-1.0MCu and HA-1.5MCu microbeads on BMMSCs may help us to use these microbeads as a good repair material for bone defects.

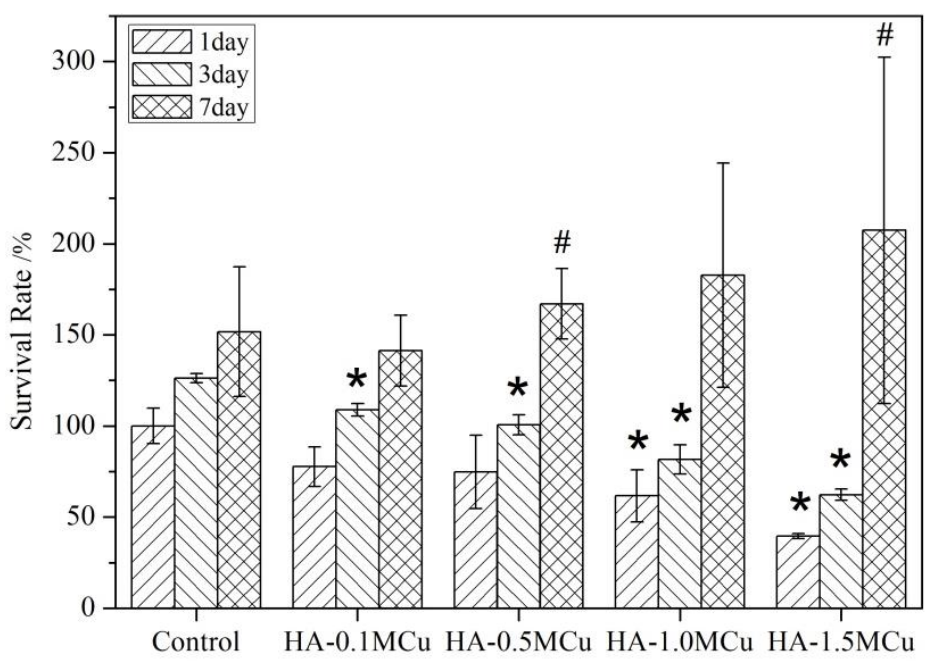

Figure 9. Cell survival rate. (* $p<0.05$, compared to control group; $\# p<0.05$, compared to day 1$)$.

In general, microspheres with higher copper content (HA-1.5MCu) have higher antibacterial activity, which may play a good role in the prevention of wound infection caused by traumatic wounds or surgical implantation, but the specific antibacterial prevention of wounds still needs further research.

\section{Conclusions}

In this paper, a facile method for preparing HA ceramic microbeads is established. Compared with microbeads with low copper doping amount, microbeads with high copper doping amount have rougher surface structure, which are of great significance in biological properties, including biodegradation, proliferation and antibacterial. Differences in surface structure also significantly affect biodegradation, while changes in microstructure have little effect on antimicrobial activity. In addition, the cell survival rate performance of $\mathrm{HA}-1.5 \mathrm{MCu}$ microbeads on day 7 is good. Considering the good degradation, antibacterial performance and cell survival rate on day 7 of HA-1.5MCu microbeads, $1.5 \mathrm{~mol} / \mathrm{L} \mathrm{CuSO}_{4}$ as the curing solution may be the best choice for the scaffold material with high biological activity. The Cu-doped hydroxyapatite microbeads produced by a pneumatic printing method is cost-effective and has good antibacterial performance and cell compatibility. Hence, it could be used as an effective filling material in repairing bone and tooth defects.

Author Contributions: Literature search, Y.L.; study design, F.A., W.L., C.C. and K.Z.; data collection, W.C., J.Z., Y.L. and K.Y.; data analysis, W.C., J.Z., K.Y. and K.Z.; manuscript writing, W.C., J.Z. and K.Z..

Funding: This research was funded by Key Laboratory of Lightweight and high strength structural materials of Jiangxi Province grant number 20171BCD40003. Kui Zhou was supported by the China Scholarship Council (No. 201808360279). 
Acknowledgments: This work was supported by Key Laboratory of Lightweight and high strength structural materials of Jiangxi Province (No. 20171BCD40003). Kui Zhou was supported by the China Scholarship Council (No. 201808360279).

Conflicts of Interest: The authors declare no conflict of interest.

\section{References}

1. Vallet-Regí, M.; González-Calbet, J.M. Calcium phosphates as substitution of bone tissues. Prog. Solid State Chem. 2004, 32, 1-31. [CrossRef]

2. Hossain, K.M.Z.; Patel, U.; Ahmed, I. Development of microspheres for biomedical applications: A review. Prog. Biomater. 2015, 4, 1-19. [CrossRef] [PubMed]

3. Yan, Z.-P.; Lin, G.; Zhao, H.-Y.; Dong, Y.-H. An experimental study and clinical pilot trials on Yttrium-90 glass microspheres through the hepatic artery for treatment of primary liver cancer. Cancer 1993, 72, 3210-3215. [CrossRef]

4. Giannoudis, P.V.; Faour, O.; Goff, T.; Kanakaris, N.; Dimitriou, R. Masquelet technique for the treatment of bone defects: Tips-tricks and future directions. Injury 2011, 42, 591-598. [CrossRef]

5. Fraga, C.G. Relevance, essentiality and toxicity of trace elements in human health. Mol. Aspects Med. 2005, 26, 235-244. [CrossRef] [PubMed]

6. Rath, S.N.; Brandl, A.; Hiller, D.; Hoppe, A.; Gbureck, U.; Horch, R.E.; Boccaccini, A.R.; Kneser, U. Bioactive copper-doped glass scaffolds can stimulate endothelial cells in co-culture in combination with mesenchymal stem cells. PLoS ONE 2014, 9, e113319. [CrossRef]

7. Liu, C.; Fu, X.; Pan, H.; Wan, P.; Wang, L.; Tan, L.; Wang, K.; Zhao, Y.; Yang, K.; Chu, P.K. Biodegradable $\mathrm{Mg}-\mathrm{Cu}$ alloys with enhanced osteogenesis, angiogenesis, and long-lasting antibacterial effects. Sci. Rep. 2016, 6, 27374. [CrossRef]

8. Mehtar, S.; Wiid, I.; Todorov, S.D. The antimicrobial activity of copper and copper alloys against nosocomial pathogens and Mycobacterium tuberculosis isolated from healthcare facilities in the Western Cape: An in-vitro study. J. Hosp. Infection 2008, 68, 45-51. [CrossRef]

9. Nam, P.T.; Thom, N.T.; Phuong, N.T.; Xuyen, N.T.; Hai, N.S.; Anh, N.T.; Dung, P.T.; Thanh, D.T.M. Synthesis, characterization and antimicrobial activity of copper doped hydroxyapatite. Vietnam J. Chem. 2018, 56, 672-678.

10. Pogosova, M.A.; Kazin, P.E.; Tretyakov, Y.D. Synthesis and characterisation of copper doped Ca-Li hydroxyapatite. Nucl. Instrum. Methods Phys. Res., Sect. B 2012, 284, 33-35. [CrossRef]

11. Li, Y.; Ho, J.; Ooi, C.P. Antibacterial efficacy and cytotoxicity studies of copper (II) and titanium (IV) substituted hydroxyapatite nanoparticles. Mater. Sci. Eng. C 2010, 30, 1137-1144. [CrossRef]

12. Zhou, K.; Zhang, X.; Chen, Z.; Shi, L.; Li, W. Preparation and characterization of hydroxyapatite-sodium alginate scaffolds by extrusion freeforming. Ceram. Int. 2015, 41, 14029-14034. [CrossRef]

13. Yamaguchi, K.; Hirano, T.; Yoshida, G.; Iwasaki, K. Degradation-resistant character of synthetic hydroxyapatite blocks filled in bone defects. Biomaterials 1995, 16, 983-985. [CrossRef]

14. Chen, Z.; Zhang, X.; Yang, Y.; Zhou, K.; Wragg, N.; Liu, Y.; Lewis, M.; Liu, C. Fabrication and characterization of 3D complex hydroxyapatite scaffolds with hierarchical porosity of different features for optimal bioactive performance. Ceram. Int. 2017, 43, 336-344. [CrossRef]

15. Anaya-Esparza, L.M.; Montalvo-González, E.; González-Silva, N.; Méndez-Robles, M.D.; Romero-Toledo, R.; Yahia, E.M.; Pérez-Larios, A. Synthesis and characterization of $\mathrm{TiO}_{2}-\mathrm{ZnO}-\mathrm{MgO}$ mixed oxide and their antibacterial activity. Materials 2019, 12, 698. [CrossRef]

16. Zhang, J.; Zhao, S.; Zhu, M.; Zhu, Y.; Zhang, Y.; Liu, Z.; Zhang, C. 3D-printed magnetic Fe ${ }_{3} \mathrm{O}_{4} / \mathrm{MBG} / \mathrm{PCL}$ composite scaffolds with multifunctionality of bone regeneration, local anticancer drug delivery and hyperthermia. J. Mater. Chem. B 2014, 2, 7583-7595. [CrossRef]

17. Guan, J.; Fujimoto, K.L.; Sacks, M.S.; Wagner, W.R. Preparation and characterization of highly porous, biodegradable polyurethane scaffolds for soft tissue applications. Biomaterials 2005, 26, 3961-3971. [CrossRef]

18. Zou, C.; Weng, W.; Deng, X.; Cheng, K.; Liu, X.; Du, P.; Shen, G.; Han, G. Preparation and characterization of porous $\beta$-tricalcium phosphate/collagen composites with an integrated structure. Biomaterials 2005, 26, 5276-5284. [CrossRef] 
19. Hsu, Y.-K.; Yu, C.-H.; Chen, Y.-C.; Lin, Y.-G. Hierarchical $\mathrm{Cu}_{2} \mathrm{O}$ photocathodes with nano/microspheres for solar hydrogen generation. RSC Adv. 2012, 2, 12455-12459. [CrossRef]

20. Khiri, M.Z.A.; Matori, K.A.; Zaid, M.H.M.; Abdullah, C.A.C.; Zainuddin, N.; Alibe, I.M.; Rahman, N.A.A.; Wahab, S.A.A.; Azman, A.Z.K.; Effendy, N. Crystallization behavior of low-cost biphasic hydroxyapatite/ $\beta$-tricalcium phosphate ceramic at high sintering temperatures derived from high potential calcium waste sources. Results Phys. 2019, 12, 638-644. [CrossRef]

21. Radovanović, Ž.; Jokić, B.; Veljović, D.; Dimitrijević, S.; Kojić, V.; Petrović, R.; Janaćković, D. Antimicrobial activity and biocompatibility of Ag+- and $\mathrm{Cu} 2+$-doped biphasic hydroxyapatite/ $\alpha$-tricalcium phosphate obtained from hydrothermally synthesized $\mathrm{Ag}^{+}$- and $\mathrm{Cu}^{2+}$-doped hydroxyapatite. Appl. Surf. Sci. 2014, 307, 513-519. [CrossRef]

22. Cuozzo, R.C.; da Rocha Leão, M.H.M.; de Andrade Gobbo, L.; da Rocha, D.N.; Ayad, N.M.E.; Trindade, W.; Costa, A.M.; da Silva, M.H.P. Zinc alginate-hydroxyapatite composite microspheres for bone repair. Ceram. Int. 2014, 40, 11369-11375. [CrossRef]

23. Yasuyuki, M.; Kunihiro, K.; Kurissery, S.; Kanavillil, N.; Sato, Y.; Kikuchi, Y. Antibacterial properties of nine pure metals: A laboratory study using Staphylococcus aureus and Escherichia coli. Biofouling 2010, 26, 851-858. [CrossRef]

24. Montero, D.A.; Arellano, C.; Pardo, M.; Vera, R.; Gálvez, R.; Cifuentes, M.; Berasain, M.A.; Gómez, M.; Ramírez, C.; Vidal, R.M. Antimicrobial properties of a novel copper-based composite coating with potential for use in healthcare facilities. Antimicrob. Resist. In. 2019, 8, 3. [CrossRef]

25. Li, Y.; Wang, J.; Wang, Y.; Du, W.; Wang, S. Transplantation of copper-doped calcium polyphosphate scaffolds combined with copper (II) preconditioned bone marrow mesenchymal stem cells for bone defect repair. J. Biomater. Appl. 2018, 32, 738-753. [CrossRef]

26. Ingle, A.P.; Duran, N.; Rai, M. Bioactivity, mechanism of action, and cytotoxicity of copper-based nanoparticles: A review. Appl. Microbial. Biotechnol. 2014, 98, 1001-1009. [CrossRef]

(C) 2019 by the authors. Licensee MDPI, Basel, Switzerland. This article is an open access article distributed under the terms and conditions of the Creative Commons Attribution (CC BY) license (http://creativecommons.org/licenses/by/4.0/). 